\title{
TRANSLATING EVIDENCE ABOUT OCCUPATIONAL CONDITIONS INTO STRATEGIES FOR PREVENTION
}

D K Verma, J T Purdham, H A Roels

$\mathrm{E}$ xposure to chemical, physical, and biological agents in the workplace can result in adverse effects on workers ranging from simple discomfort and irritation to debilitating occupational diseases such as lung fibrosis, neuropathy, deafness, organ damage, and cancers of various sites. Such conditions result from excessive exposure and can only be avoided through adequate control measures which will prevent or minimise exposure to harmful agents. The process by which evidence of hazardous occupational conditions and information on control methods is translated into actual implementation of control and prevention strategies to eliminate or dramatically reduce the hazardous exposure and associated health risk, is often the result of a subtle compromise between scientific evidence of varying degree of certainty, interest group lobbying, and feasibility considerations.

\section{CONTROL STRATEGIES FOR OCCUPATIONAL HAZARDS}

The development of control strategies for occupational hazards takes place at two levels: the societal level and workplace level. The information needs for these two levels can be quite different although there is some overlap. At the societal level, the control measures are usually through regulatory action. Regulatory action first requires strong scientific evidence that a harmful effect is caused by a particular workplace agent. Information is then needed on possible exposure-effect relationships as well as a number of workplace demographics. At the workplace level information is needed on the nature of the hazard, where it is likely to be encountered, and the available options for risk reduction. Scientific evidence can vary in terms of its nature, quantity, and strength and there is no fixed yardstick for what is required for regulatory and other actions because there are also many additional factors which may influence the decision on the necessity of control and the degree required.

Scientific evidence may derive from toxicological and epidemiological studies. Toxicological studies on animals can provide information on causal agents and give some indication of possible dose-response relationships for risk assessment purposes. In addition they can provide information on entry, distribution, metabolism, and excretion pathways for toxic substances, useful in establishing biological monitoring methods for assessment of exposure to toxicants and relating health effects to internal dose. Epidemiology on the other hand provides information directly on the effects of chemicals and other agents on humans. It can sometimes give an indication of exposure-response relation and this is extremely important evidence when regulatory action is being considered. Supplementary evidence may be obtained from surveillance programmes, including hazard surveillance, exposure measurement, and medical surveillance. These programmes, especially when used together, are important in the recognition of the need for controls and the assessment of their effectiveness and, as such, are usually considered components of a control strategy. However, on occasion, as in the case of vinyl chloride for example, they can provide the initial alert to potential harm. Medical surveillance programmes allow occupational physicians and nurses to recognise recurring patterns of illness in certain groups of employees. Such observations may lead to direct recognition of a new hazard, provide impetus for research, or recognise the adequacy or otherwise of any implemented controls. Hazard surveillance and measurement of workplace exposures produce, in a systematic way, documented evidence of existing workplace conditions, providing information on potentially hazardous situations, the adequacy of any existing controls, or the need to introduce controls where none exist.' It can also provide exposure information which is useful in the investigation of exposure-response relationships.

In addition anecdotal data may come from the plant physician in the form of isolated clinical cases or from worker health and safety representatives and trade union officials who are often the recipients of persistent health complaints by workers. The collection and organisation of such information may produce evidence of workplace conditions in need of assessment and possible control.

Correspondence to:

ma; Program in Occupational Health and Environmental Medicine McMaster University, 1200 Main Street West, HSC-3H50, Hamilton, Ontario, Canada L8N 3ZS;

vermadk@mcmaster.ca

\section{REGULATION AND OCCUPATIONAL EXPOSURE LIMITS}

Society's method for dealing with occupational hazards is through regulatory control of the offending substance or process. Once adverse health effects of a substance or agent present in the workplace have been identified, the regulatory strategies available range from an outright ban on 


\section{Abbreviations}

ACGIH: American Conference of Governmental Industrial Hygienists

COSHH: Control of Substances Hazardous to Health

CNS: central nervous system

DFG: Deutsche Forschungsgemeinschaft

EPA: Environmental Protection Agency

HSE: Health and Safety Executive

IARC: International Agency for Research on Cancer

IOELVs: indicative occupational exposure limit values

MSDS: material safety data sheets

MAK: maximum concentrations at the workplace

NIOSH: National Institute of Occupational Safety and Health

OELs: occupational exposure limit

OSHA: Occupational Safety and Health Administration

PVC: polyvinyl chloride

SCOEL: Scientific Committee on Occupational Exposure Limits

TLV: threshold limit value

TWA: time weighted average

the manufacture and use of the substance, to the establishment of regulated limits for exposure, to publication of guidelines on the safe use of the substance. By far the most common strategy is the imposition of regulated exposure limits with, for particularly dire hazards, requirements for supplementary strategies such as surveillance. For over 50 years now, exposure limits have been established and published as "threshold limit values" (TLVs) for chemical substances and physical agents or as "biological exposure indices" by the American Conference of Governmental Industrial Hygienists ${ }^{2}$ as a guide to good professional practice. Many jurisdictions simply adopted these guidelines wholesale when developing their occupational health and safety legislation and in a substantial number they still form the backbone of legislated limits to exposure. Indeed some jurisdictions like the Occupational Safety and Health Administration (OSHA) in the USA are, to a great extent, locked in to outdated standards because they adopted standards many years ago and the process for updating them is extremely convoluted and time consuming. Other jurisdictions have moved on and now have in place mechanisms for establishment of their own standards. For example the Health and Safety Executive (HSE) in the UK enforces consensus occupational exposure limits set by the tripartite Health and Safety Commission and recently adopted a new approach laid down in the Control of Substances Hazardous to Health (COSHH) Regulations. ${ }^{3}$ In Germany, the Deutsche Forschungsgemeinschaft's (DFG) Commission for the Investigation of Health Hazards of Chemical Compounds in the Work Area develops the MAK values (maximum concentrations at the workplace) and the BAT values (biological tolerance values for working materials). ${ }^{4}$ The first consensus document may soon be available from the European Union's Scientific Committee on Occupational Exposure Limits (SCOEL) that defines health based occupational exposure limits (OELs) which are to be implemented as indicative occupational exposure limit values (IOELVs) via IOELV directives. ${ }^{5}$ Where permissible exposure limits are established, then measurement of exposure and comparison with these limits provides evidence of whether the quality of the workplace environmental conditions are likely to be safe or unacceptable.

Evidence required for regulatory action and information on whether existing occupational conditions are acceptable or

\begin{tabular}{ll}
\hline Box 1 Evidence & \\
\hline Source & Type \\
\hline Toxicology & $\begin{array}{l}\text { Causal agent } \\
\text { Dose-effect/response data } \\
\text { Toxicity and disease mechanisms } \\
\text { Candidate biomarkers for biological } \\
\text { monitoring } \\
\text { Causal agent/process } \\
\text { Exposure-effect/response data } \\
\text { Validation of biomarkers for biological } \\
\text { monitoring }\end{array}$ \\
Occupational medicine & $\begin{array}{l}\text { Clinical observation of disease from routine } \\
\text { or specific medical surveillance } \\
\text { Exposure measurements in comparison to } \\
\text { control limits } \\
\text { Reports of complaints or ill health among } \\
\text { workers }\end{array}$ \\
Unions/workers &
\end{tabular}

harmful, can come from a variety of sources and varies in strength (box 1). However, the decision that the evidence is considered sufficient to warrant action and the manner in which relevant information is translated into an effective strategy for prevention is almost always influenced by a number of factors (box 2). Important among these is the strength of the scientific evidence, the nature of the effect, and the scope and magnitude of the problem. The answer to whether or not a substance causes harm is rarely characterised by scientific certainty. Toxicological data has to be extrapolated from animals to humans and usually from high to low dose. Epidemiological studies often have many confounders, design weaknesses and poor exposure data, especially when exposures occurred many years in the past. The nature of the hazard is also important, with severe outcomes like cancer or neurodegenerative diseases being regarded as in more urgent need for control measures than, for example, a respiratory irritant. The number of people affected also influences the decision as does the importance of a substance to the economy, especially when a ban is the control strategy being considered. This ensures that there will be debate about the adequacy of the scientific evidence, which can lead to delay. Subsequently, should the decision to regulate be made, a debate about the technical and economic feasibility of implementation of controls will influence which of the spectrum of regulatory options will be chosen for control of the substance (box 3).

\section{WORKPLACE CONTROL STRATEGIES}

Workplace controls may be instigated in response to information and support from some suppliers as part of product stewardship programmes, or as part of responsible care programmes promoted by industry associations, ${ }^{6}$ but are much more likely to arise as a result of governmental regulation. The simple introduction of regulations alone, including occupational exposure limits, may not be sufficient to persuade employers to introduce controls for chemicals on their premises which are subject to the new regulations. Topping et al have recently described a market research study carried out in the UK to determine employer perception of occupational exposure limits and the extent to which they influence the selection of measures to control exposure. ${ }^{7}$ Although the response rate in the study was low (16\%), the findings are interesting. Among a chemical user group awareness and understanding of occupational exposure limits was limited, with only $19 \%$ of the total user group and 53\% of 
Box 2 Influencing factors

\begin{tabular}{lll}
\hline Scientific/technical factors & Social factors & Economic factors \\
\hline Strength of scientific evidence & Nature of disease & Cost of control options \\
Ongoing research & Human cost & Impact on industry \\
Magnitude and scope of problem & Effect on community & Impact on consumers \\
Control options & Public perception & Trade agreements \\
-availability & Media interest & Business-labour relations \\
-technical feasibility & Influence of unions/business on government & \\
Information & Philosophy of government & \\
-availability & & \\
-generation and dissemination & & \\
Suppliers material safety data sheets (MSDS) and & & \\
labels & & \\
Availability of occupational hygiene professionals & &
\end{tabular}

heavy users having any real understanding. It would appear that any exposure control strategy relying on legislation of exposure limits would need to also include a strong, effective employer and a public education campaign.

Once awareness of a potential hazard is developed at a workplace and the possible need for controls recognised, there is an immediate need for information. Where is the chemical or agent likely to be encountered? What are the current exposure levels? Are present controls adequate to meet the new regulated limits? What options are available for the introduction of new controls and what strategies should be included in an ongoing control programme? The options available range from substitution of the material or process with less hazardous alternatives to the introduction of engineering controls to limit exposure, the use of personal protective equipment, the introduction of education and training programmes, and the implementation of monitoring programmes. If substitution of material or process is to be considered then information is needed on the adequacy and availability of suitable alternatives and their costs. If engineering controls are to be used, information is needed on technical feasibility and economic factors. For education and training programmes, is there adequate information on the nature of the hazard and work practices for minimisation of exposure? For monitoring programmes, which provide feedback on the success or otherwise of control efforts, are there standard methods for air monitoring, biological monitoring, and medical surveillance? What are the professional occupational health resources available to the company (for example, occupational hygienists and physicians)?

\begin{tabular}{|ll|}
\hline Box 3 Prevention strategies & \\
\hline Regulatory & Workplace \\
\hline Ban on use/manufacture & Engineering controls \\
Exposure limit with specific regulation & -ventilation \\
Exposure limit alone & -process isolation \\
Guidelines & -process modifications \\
& Substitution with less \\
& hazardous materials \\
& Personal protective \\
& equipment \\
& Work practice changes \\
& Education and training \\
& Surveillance \\
& -hazard surveillance \\
& -exposure level monitoring \\
& -biological monitoring \\
& -medical monitoring \\
\hline
\end{tabular}

Company records should be able to supply information on matters such as the location of a chemical and any exposure measurements. The technical literature, government publications and guidance notes may be helpful for engineering controls, as well as for monitoring options. Right to know legislation in many jurisdictions has led to the use of labels and the furnishing of material safety data sheets (MSDS) for each substance, detailing the nature of hazards, the composition of mixtures, and the methods for control, including personal protective equipment.

Questions such as these arising after attention has been brought to a substance often spur research efforts related to the evaluation and control of the particular agent as well as prompting further research on what other effects might be caused by the agent. Results of all of this work are presented at conferences and symposia as well as in the scientific literature. All of this then provides feedback to the decision making processes at the regulatory and workplace level. The process of translating evidence of occupational conditions into the strategies for control can, therefore, best be visualised as an interrelated three box process where box 1 represents the sources of evidence and information, box 2 the influencing factors, and box 3 the possible strategies for prevention and control. Feedback loops exist between the boxes. A number of examples drawn from well known hazardous occupational agents will serve to illustrate how evidence has been translated into strategies for control to various degrees; in some cases very thoroughly and expeditiously and in others only minimally, or the hazard ignored for long periods of time.

\section{SELECTED CASE STUDIES}

The following examples have been selected to illustrate various issues encountered in the introduction of preventive control strategies:

- vinyl chloride and liver cancer

- 2-naphthylamine and bladder cancer

- asbestos, asbestosis, lung cancer, and mesothelioma

- silica, silicosis, and lung cancer

- benzene and leukaemia

- flour dust and baker's asthma

- noise and hearing loss

- manganese, parkinsonism, and pneumonia

\section{Vinyl chloride}

In January 1974, physicians from BF Goodrich reported to the US National Institute of Occupational Safety and Health (NIOSH) that they had observed an unusual cluster of deaths from liver angiosarcomas for employees in their polyvinyl chloride (PVC) manufacturing plants. Epidemiological studies 
later confirmed that exposure to vinyl chloride monomer in PVC plants was associated with this disease. However, because of the rarity of the tumour in the general population, NIOSH was able to immediately decide that it was dealing with a new occupational disease. In February, OSHA called an informal fact finding hearing where the findings were discussed and a toxicologist, Maltoni, was invited to present his preliminary animal data. The data showed that exposure of rats to vinyl chloride induced angiosarcomas of the liver as well as other cancers, confirming the causal role of vinyl chloride. A process was immediately put in place to develop regulatory action which included input from employers and workers.

The standard being followed in most jurisdictions at the time was 200 parts per million (ppm) suggested by the influential American Conference of Governmental Industrial Hygienists (ACGIH). Industry representatives proposed the standard be lowered to $50 \mathrm{ppm}$, since Maltoni had found no tumours at the $50 \mathrm{ppm}$ level. However, NIOSH argued that the number of animals in the Maltoni study was too small to allow a safe level to be defined and consequently proposed that there be no exposure to measurable amounts of vinyl chloride monomer. Where measurable amounts were encountered, air supplied respirators were to be worn. There were also requirements for a control plan and for regular monitoring of exposure. OSHA promulgated the standard in October 1974 and it was effective January 1975, but applied only to polymerisation plants which appeared to be the main problem.

Maltoni's work on animals continued and eventually led to the study of the carcinogenic effect at concentrations of vinyl chloride ranging from 30000 to $1 \mathrm{ppm}$ and provided the dose-response data necessary for risk assessment and the establishment of an appropriate exposure level, which OSHA set at 1 ppm, applicable to all operations where vinyl chloride exposure was possible. ${ }^{8}$ Similar regulatory efforts were followed in other countries, relying upon the same data, but not necessarily resulting in the same standard, demonstrating the tempering of scientific data by socioeconomic considerations. In most cases the airborne standard was coupled with requirements for medical surveillance of employees as well as requirements for exposure monitoring and education as part of an overall control programme.

In the USA the PVC industry argued strongly that the introduction of these restrictive regulations would result in the effective destruction of the industry, since the cost of the necessary control measures would result in many plant closures. NIOSH researched the various methods for PVC production and produced a publication on engineering control options for these processes. ${ }^{9}$ Thus, government made efforts to produce information which could be used by industry in meeting the regulations. Of course, there is a flourishing PVC industry in the USA today, as there is elsewhere.

All of this attention spawned a great deal of research activity aimed at confirming the initial findings of angiosarcoma of the liver, determining whether vinyl chloride exposure caused cancer of other sites, determining whether communities around PVC facilities were at risk of cancer and birth defects, developing methods for engineering control, and developing improved methods for monitoring exposure to vinyl chloride.

Vinyl chloride provides an example where regulatory action followed reporting of scientific evidence in a more rapid fashion than has been seen for many other substances. This happened because the scientific evidence was so compelling. It is a case where attention was first drawn to the problem by some very astute physicians making observations on the health records of plant employees. It was also possible because Mal- toni had already started work on animal models, which was eventually thoroughly developed to provide reliable doseresponse data. Although evidence was also gathered from other quarters, mostly this was not really necessary for demonstrating causality, because the tumour was rare in the general population. It also represents a case where government worked to provide industry with information needed to engineer exposures to the required level and also provided funding for research on the many other aspects of this chemical and its control requirements.

\section{2-Naphthylamine}

As a class, aromatic amines have long been suspected of containing several members which are carcinogenic. Of these, the bladder carcinogenicity of 2-naphthylamine (also known as $\beta$-naphthylamine) has been the longest and best established. Again, it was the observation of a surgeon, Rehn, in 1895 that there was an undue incidence of bladder cancer in workers engaged in magenta manufacture that provided the initial alert. Although he wrongly attributed the effect to aniline exposure, he succeeded in focusing attention on the problem. Many similar reports followed from around the world, but it was not until 1938 that Huper and colleagues conclusively demonstrated that 2-naphthylamine, in its commercially available form, caused bladder tumours in dogs and this was later confirmed by Brauer in 1943. The Association of the British Chemical Manufacturers subsequently funded an epidemiological study by Case, which definitively showed that workers exposed to 2-naphthylamine and other aromatic amines, were at greatly increased risk of bladder cancer. ${ }^{10}$

In response to this information, different strategies were adopted by regulatory agencies in the UK and the USA. In the USA, the use of carcinogens including 2-naphthylamine was regulated to minimise exposure under the OSHA Act of 1970. ACGIH had always classified this material as a carcinogen for which there was no exposure limit and for which there should be no exposure. In the UK bladder cancer was made a prescribed industrial disease in 1953 and workers who could show they had been exposed to 2-naphthylamine could claim compensation. They could also be awarded court damages if they could show the employer knew about the bladder cancer risk and did not take appropriate steps. This constituted a major influencing factor on the approach to workplace control adopted by industry. The two most affected industries were the rubber industry and the dyestuffs industry. In the UK 2-naphthylamine was used in the manufacture of an antioxidant Nonox-S for use in the rubber industry. As evidence of the carcinogenicity of 2-naphthylamine grew, the manufacturer of Nonox-S withdrew it from production and its use ceased. Similarly alternatives were sought for the replacement of 2-naphthylamine as an intermediate in the dyestuffs industry and in the end, in 1967, the government prohibited the manufacture and use of this compound. Use of substances containing less than $1 \%$ was allowed with strict controls including mandatory medical surveillance. In the USA, the substance was not banned but strict control essentially has had the same effect since, according to OSHA, for many years now 2-naphthylamine has only been used for research purposes.

The key influencing factors were the strength of the scientific evidence, the fact that these materials represented only a small fraction of the chemical industry output, the availability of suitable alternative materials and processes, and the technical feasibility of the replacement strategies.

This represents a case where scientific evidence was developed and strengthened slowly over many years, definitively 
identifying a causal carcinogenic agent which eventually, but not immediately, resulted in its removal from commerce in some jurisdictions and through strict regulation in others, resulting in the same effect. This was facilitated by the availability of alternative materials and processes and therefore minimal economic impact of its removal from commerce.

\section{Asbestos, asbestosis, and cancers}

Asbestos is a general term applied to the fibrous form (asbestiform) of certain hydrated silicate minerals. It has enjoyed ubiquitous use because of its very highly desirable properties of insulation against heat, cold and noise; incombustibility; dielectric properties; high tensile strength; resistance to alkalis and acids; and flexibility and spinnability. Among the six varieties of commercial asbestos, chrysotile, amosite, and crocidolite have been produced and used most widely. Because of the widespread use of asbestos, a large number of people have been occupationally exposed to it in operations such as mining and milling, manufacture and use of asbestos cement pipe, flooring and friction products, use in thermal insulation, asbestos textile products, paint fillers and spraying of asbestos for fire proofing, and improved acoustical qualities.

There is well established evidence for the link between exposure to asbestos and diseases such as asbestosis, mesothelioma, and cancer of the lung and other sites. Asbestos is one of the most important occupational carcinogens, accounting for almost half of all occupational cancers.

Asbestosis was described in the UK in 1907 and the occurrence of lung cancer in asbestos workers was reported in the 1930s and was well established by the 1950s. The evidence for asbestos causing asbestosis, cancers, and mesothelioma came from sources such as clinical observations (radiological and pathological), necropsy, animal studies, and epidemiological studies. Mesothelioma, for example, is thought to be almost exclusively related to asbestos exposure. The influencing factors in the formulation of strategies for prevention included somewhat slower acceptance by the industry of asbestos' carcinogenic potency. Figure 1 illustrates that well into the mid 1970s it was possible to find common operations that generated asbestos aerosols in an uncontrolled manner. While there is now little disagreement that exposure to asbestos can cause these diseases, there has been strong debate on the true extent of the risk, whether all types of asbestos are equally capable of causing these diseases and, for lung cancer, at one time, whether the disease was seen in the absence of asbestosis. Such arguments resulted in significant delay in the introduction of stricter control and prevention strategies. There are numerous publications available, but the readers would get a good grasp of the arguments in an exchange of letters published in 1991. ${ }^{11}$

The evidence that the hazard of asbestos exposure is better assessed by measuring asbestos fibre of certain size by microscopy than by the older method of measuring dust concentration led to the institution of standards and a prevention strategy based on measurement of fibres thinner than $3 \mu \mathrm{m}$ in diameter and longer than $5 \mu \mathrm{m}$ in length. ${ }^{12}$ The evidence that some asbestos diseases such as mesothelioma are not dose related led to concern about asbestos contamination from sprayed material and other sources in buildings and schools. This has led to a flurry of remedial activity for this non-occupational hazard. Billions of dollars have been spent in removing asbestos from public and other buildings, despite the fact that the evidence is not equivocal that such non-occupational asbestos exposure constitutes a serious risk. However, the prevention strategies that have been instituted

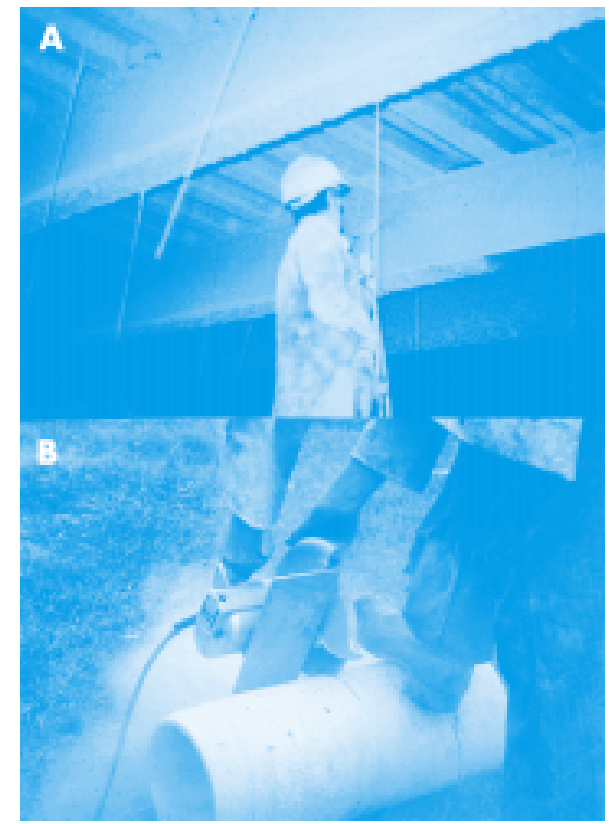

Figure 1 Uncontrolled asbestos exposure. (A) Spraying asbestos fireproofing insulation. (B) Cutting transit pipe containing chrysotile and crocidolite asbestos.

have been greatly influenced by political, societal, and public perception of the harm resulting from asbestos exposure.

Regulatory action has seen the adoption of stricter and stricter exposure standards, now set in North America at 0.1 fibres/ml for all types of asbestos, a huge reduction from the recommended exposure limit of ACGIH in early 1970 of 5 million particles per cubic foot (mppcf), which is very roughly equivalent to 30 fibres $/ \mathrm{ml}$. The European Union has proposed a total ban on the importation and use of asbestos as a prevention strategy. Interestingly, Canada, one of the leading producers of chrysotile asbestos, has actively lobbied against this ban. This is ironic given that Canada itself chose to ban the import of crocidolite asbestos, mined chiefly in South Africa. Within Canada, as elsewhere in the developed world, there is strict regulation and control of the use of asbestos, which has resulted in a huge reduction in its use. Also a massive effort has been put into remediation of in-place asbestos in public buildings and industrial operations. The slow development of regulatory action may well have been influenced by the potentially huge economic impact of removing asbestos products from commerce, because the material enjoyed widespread use and there was a lack of suitable alternatives for many of its uses, until regulation ensured that research emphasis would be placed on their identification. Asbestos continues to be widely used in developing countries, despite the internationally available evidence of harm. For economic and other reasons, preventive strategies are not as well developed and it can reasonably be predicted that these nations will witness an epidemic of asbestos related diseases for decades to come.

\section{Silica, silicosis, and lung cancer}

Exposure to silica and its attendant health risks occurs in numerous industries, including quarrying, stone cutting, mining and tunnelling, foundries, ceramics, abrasives, glass making, brick making and construction. It is well established that prolonged occupational exposure to silica (free crystalline silica) can cause silicosis, a fibrotic disease of the lung. Silicosis is thought to be the longest known of the pneumoconioses. 
As silica forms the greater part of the earth crust, the potential for exposure has been there since humans took to working the land and making tools and weapons from flint. Mention of hazard of dust can be historically traced to the 1st century AD. From the 15th through the 18th century there were many references and silica hazards were fairly well recognised by early $1900 .^{13}$

As the evidence of silicosis among workers accumulated, some strategies for prevention were put in place. These included occupational hygiene measurements to assess dust concentrations, installation of engineering controls including ventilation, suppression of dust at source, medical monitoring of exposed workers, and provision of personal protective devices such as respirators.

All of these prevention strategies generally improved with the progress of time, technology, and availability of evidence of harm from health studies including animal studies and epidemiological studies. A notable change in the measurement method, for example, was when the assessment of total dust exposure by counting particles was abandoned in favour of the gravimetric measurement of respirable dust, which represents dust particles small enough to reach the alveolar region of the lung. These particles are smaller than $10 \mu \mathrm{m}$ aerodynamic diameter with $50 \%$ less than $4 \mu \mathrm{m}$. The evidence that mass concentration of respirable dust was more closely related to the risk of silicosis than particle concentration came from occupational hygiene and epidemiological studies and studies of necropsied lungs.

Measures for control of exposure have generally been put in place and improved over time in developed nations such as North America and Europe, but the same cannot be said for developing nations such as China and India or the former Soviet Block countries where high exposure and the disease is still far more prevalent. A recent epidemiological study of Chinese tin miners showed that $33.7 \%$ of the exposed cohort ( 1015 men) were identified as silicotic, a very high rate. ${ }^{14}$ Even in developed countries more remains to be done since risk of silicosis remains a significant concern. For example, use of silica in sandblasting continues to be allowed in North America, while it was banned in the UK in 1949 and in Europe in 1955.

Silica has been shown to be a carcinogen in animal studies (in rats) and there have been reports of increased lung cancer among workers with silicosis. ${ }^{15}$ These studies, which appeared in the 1980s and '90s, led the International Agency for Research on Cancer (IARC) to classify crystalline silica as a class 1 carcinogen in 1997.

The current standards are based on evidence that suggests that the risk of lung cancer appears to be limited to those with silicosis, and therefore prevention strategies to control silicosis should also control risk of lung cancer. However, the debate about whether silica is capable of causing lung cancer in the absence of silicosis is ongoing ${ }^{15}{ }^{16}$ and it will be interesting to see how it turns out and how quickly further changes in prevention strategies are made should the consensus be that silicosis is not a necessary precondition to cancer.

\section{Benzene and leukaemia}

Benzene is present in crude oil and natural gas products such as solvents, gasoline (petrol), fuels, and oils. Benzene in gasoline still averages about $2 \%$ in North America (higher in Europe). While benzene is now universally recognised as a human leukaemogen, this was not the case as little as 20 years ago, despite the fact that the first report clearly associating benzene with leukaemia was published as early as 1928 and

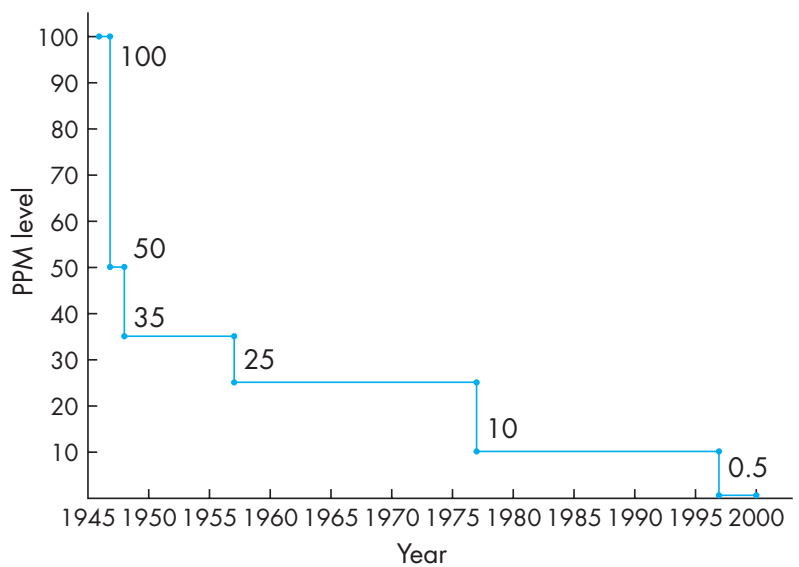

Figure 2 Chronology of ACGIH adopted exposure limits for benzene.

the first case describing haematologic toxicity was reported over 100 years ago in $1897 .{ }^{17}$

Early evidence of benzene being capable of causing leukaemia must not have been considered strong enough to be translated into control strategies with that in mind. Major improvement in workplace control of exposure seems generally not to have been made until the 1970s. Before that, the control strategy was based largely on its anaesthetic effect, not leukaemia. The chronology of adopted TLVs for benzene set by $\mathrm{ACGIH}^{2}$ shows that the TLV was $100 \mathrm{ppm}$ in the 1940s, and from 1977 until the mid 1990s it was still set at $10 \mathrm{ppm}$ for prevention of aplastic anaemia, although the leukaemogenic properties of benzene had been identified and NIOSH had recommended an exposure level of 1 ppm. Only in 1997 was the TLV reduced to the more appropriate level of $0.5 \mathrm{ppm}$ to prevent leukaemia. Figure 2 illustrates the successive decline in ACGIH adopted exposure limits for benzene over the years, which is not atypical of most substances. Why did it take so many years for evidence of leukaemia to be accepted for workplace control strategies? What were the influencing factors? One factor was undoubtedly the strength of the scientific evidence, which took time to develop, and for there to be a full understanding of the exposure-response relationship. Certainly the products which contained benzene were considered important and useful to society and the risk, relatively speaking, was not perceived to be high.

As the exposure limit was gradually reduced there was a need at the workplace for new methods of biological monitoring. As a result, determination of S-phenylmercapturic acid and $t, t$-muconic acid in urine have now replaced the old phenol in urine method which, because of high background levels, lacked the necessary sensitivity when exposures were less than about 5 ppm. ${ }^{218}$

In this case, the evidence accumulated from various sources including animal studies, biological monitoring, clinical observation, hygiene measurements, and epidemiological studies. The influencing factors were the strength of the association, societal pressure, and the technical feasibility of control. The prevention strategies that resulted included institution of medical surveillance, engineering control, and legislation of stricter occupational exposure limits to control the risk of leukaemia. 


\section{Flour dust and baker's asthmo}

Occupational exposure to flour and grain dust in bakeries can cause baker's asthma which is defined as an allergic sensitivity to inhaled flour dust. Historically, it was described by Ramazzini in 1713 and the link between allergy to flour and rhinitis and asthma was identified in the early 1900s. ${ }^{19}$ Numerous potential allergens have been implicated including wheat and other cereals, grain storage mite, and dough improver.

Longer workplace exposure to flour and cereal antigen are associated with increased risk of acquiring baker's asthma. Flour allergy has been reported to occur in $10-30 \%$ of bakers. The actual rate may be even higher since individuals with serious work related disease may leave the trade. A typical clinical history would include rhinitis followed by asthma, which tends to develop after exposure at work and improves on weekends. It has been suggested that the most advisable treatment of baker's asthma is for the person to leave the industry. ${ }^{20}$

The control of flour dust exposure in bakeries by appropriate engineering controls such as local exhaust ventilation, enclosure, etc, should be a relatively simple matter today. That baker's asthma continues to occur at an alarming rate indicates that good prevention strategies are not being put in place. This, to some extent, may be due to the predominance of small sized bakeries where owners may not be able to justify expensive engineering control or may simply be unaware of the need for control. Baker's asthma as a health effect does not have quite the same public impact as other more serious diseases such as pneumoconiosis, leukaemia, and cancers. Hence, public perception of risk and pressure for change is not as high.

A study of modern British bakeries reported in 1989 showed a high degree of respiratory symptoms along with continuing high exposure to flour dust. ${ }^{21}$ Even more recently high exposures (some as high as $110 \mathrm{mg} / \mathrm{m}^{3}$ ) have been documented in Canadian bakeries. ${ }^{22}$ These exposures are far in excess of the current ACGIH TLV of $0.5 \mathrm{mg} / \mathrm{m}^{3}$, although across jurisdictions a wide range of exposure standards are in use, even as high as $10 \mathrm{mg} / \mathrm{m}^{3}$ (UK). ${ }^{19}$ Although this variation in standards has been ascribed in part to the use of different health end points, it demonstrates again the impact of social, economic, and political factors in establishing standards.

Despite the overwhelming evidence that workplace exposure to flour dust should be controlled, prevention strategies in bakeries appear to have not been very satisfactory. While there are exposure limits established, some are clearly inadequate and little regulatory action beyond general requirements has been applied to this substance, unlike the regulatory attention given to materials such as vinyl chloride monomer and asbestos.

\section{Noise and hearing loss}

Occupational exposure to noise is widespread. Few industry workplace environments are free from noise exposure. Prolonged exposure over many years can cause hearing loss and other impairments such as tinnitus. This problem dates back to the middle ages where blacksmiths and church bell ringers were known to suffer from such impairment. Boiler maker's deafness has been cited in early literature. Interest in hearing conservation intensified as a result of the second world war, when many soldiers returned home with hearing loss. In the USA, efforts to regulate occupational exposure began in the armed forces in 1956. Promulgation of the noise standard under the Occupational Safety and Health Act of 1970 brought the issue of noise and hearing loss to prominence. Many studies of the relationship between noise and hearing loss also began to appear in the literature. Burns and Robinson in the early 1970s published work which provided the basis for occupational exposure limits. ${ }^{23}$ However, there was debate over the interpretation of these results. The evidence seems to imply that a threshold limit of $85 \mathrm{dBA}$ should be used with a $3 \mathrm{~dB}$ exchange rate-that is, an eight hour exposure at $85 \mathrm{dBA}$ is equivalent in its effect to a four hour exposure at $88 \mathrm{dBA}$. Despite this, most earlier exposure limits were set at a $90 \mathrm{dBA}$ threshold with a $5 \mathrm{~dB}$ exchange rate.

Since there are often multiple sources of noise, and since sufficient noise level reduction is often difficult to achieve through engineering control which can also be expensive, reliance is very often been placed on the use of hearing protection within a hearing conservation programme as a control strategy. Hearing conservation programmes also typically include regular audiometry, education, sign posting, and exposure monitoring.

Although today there is a much improved understanding of the mechanism of noise induced hearing loss, noise measurement methods, engineering control of noise, personal hearing protective devices, and good hearing conservation programmes, hearing loss among the exposed population is still quite prevalent..$^{24} \mathrm{~A}$ recent NIOSH document estimates that for a 40 year working lifetime exposure to noise, there will be an $8 \%$ excess risk for hearing loss at $85 \mathrm{dBA}$ and a $25 \%$ excess risk at $90 \mathrm{dBA} .^{25}$

The evidence that, at a certain noise level, hearing loss and tinnitus will occur has been well demonstrated, but the prevention strategies have not been uniformly applied across workplaces. This is likely because the health effects of hearing loss and tinnitus, although a serious handicap to affected people, is not seen in the same light as serious diseases such as cancer, leukaemia, etc. Perhaps this is because it is a slowly progressive disease, often occurring at a time of life when people are expecting a diminishment of their faculties. Another contributing factor has been the ongoing debate over the interpretation of hearing loss data in the literature, particularly the validity of the $3 \mathrm{~dB}$ exchange rate. This has led to a reluctance to establish highly restrictive exposure standards. Instead of engineering controls, reliance is placed on protective equipment, which often proves inadequate. One example of this regulatory inertia can be seen in the province of Ontario in Canada where the exposure standard in place dates back over 30 years and is set at $90 \mathrm{dBA}$ for eight hours exposure. Various draft revised regulations have been prepared over the last 25 years but none enacted.

\section{Manganese, parkinsonism, and pneumonia}

Manganese is widely distributed in nature, with pyrolusite ore $\left(\mathrm{MnO}_{2}\right)$ being the chief commercial source. Pyrolusite was known in ancient times as a bleach and a glass pigment. Today, the greatest use of manganese ores is in the production of iron, steel, and manganese alloys. Other uses include dry cell battery manufacture, soil and animal feed supplements, welding rod coatings and fluxes, and as a pigment in glass, ceramic products, dyes, and paints. Organo-manganese compounds are used in fungicides and gasoline additives which has raised public health concerns.

Until the early 1800s, manganese compounds were considered to be relatively harmless. In 1837, Couper was the first to present a clinical description of chronic manganese intoxication (manganism) in five workers at a pyrolusite ore mill, and to associate inhalation of manganese dust with a neurological 


\section{Key points}

The process by which the evidence about hazardous occupational conditions gets translated into strategies for prevention in workplaces is often a result of subtle compromises between scientific evidence and socioeconomic factors

The evidence is largely derived from epidemiological and toxicological investigations and from observations by occupational health professionals and workplace parties such as unions

- The translation of the evidence into control strategies is influenced by a number of factors, including: the strength of the scientific evidence and technical factors such as availability and feasibility of control options; social factors such as human cost, public perception of risk, and government philosophy; and economic factors such as cost of controls, impact on competitive advantage, and influence of trade agreements

- The strategies for prevention include regulatory strategies, which range from provision of guidelines, to establishment of exposure limits, to the ban on use of substances; and at the workplace level, strategies for translating these are into engineering, occupational hygiene, medical and administrative controls

- Cases presented illustrate that, in the past, there often appears to have been a very long time period between the first appearance of evidence linking an agent to a disease and the eventual appearance of effective prevention strategies. It is hoped that in the future evidence of workplace hazards will be much more rapidly, uniformly, and globally translated into prevention control strategies

condition currently considered as an extrapyramidal syndrome. ${ }^{26}$ Inhalation of manganese dust was subsequently found to be associated also with pneumonia and pneumonitis. During the 1950s, high manganese dust levels in mines (introduction of dry pneumatic drilling) and in other industrial operations, such as ore mills, iron and steel production, and battery manufacture led to outbreaks of manganism. In the 1960s evidence of respiratory and neurological effects at much lower concentrations than had been observed in these industries (sometimes in excess of $100 \mathrm{mg} / \mathrm{m}^{3}$ ) led to the ACGIH adopting a TLV ceiling limit of $5 \mathrm{mg} / \mathrm{m}^{3}$ in 1970 .

In the early 1980s, a World Health Organisation (WHO) task group and the US Environmental Protection Agency (EPA) arrived at directly opposite opinions on what the available evidence indicated. WHO found that the evidence pointed to neurological effects at $2-5 \mathrm{mg} / \mathrm{m}^{3}$ and probably down to less than $1 \mathrm{mg} / \mathrm{m}^{3}$ with no possibility of establishing an exposureeffect relationship for respiratory effects, while the $\mathrm{EPA}^{27}$ found respiratory effects at less than $1 \mathrm{mg} / \mathrm{m}^{3}$, with equivocal or negative results below this level for central nervous system (CNS) effects. This illustrates the extent of uncertainty in risk assessment due to the poor quality of data available at that time. This probably helped stimulate the tremendous progress in the last 20 years which has seen improved occupational hygiene exposure assessment and control, greater insight into toxicokinetic aspects of inhaled manganese dust, enhanced understanding of the pathophysiology of a manganese induced parkinsonian syndrome, improvement in detection of CNS effects at a pre- or subclinical stage, and in epidemiological study design.

A decisive step towards a more appropriate inhalation exposure standard, and consequent control, came with the recognition that the neurotoxic potential of manganese should form the basis of the occupational exposure standard. Two cross sectional epidemiological studies by Roels and colleagues $^{28} 29$ conducted in the 1980 s on workers with a mean exposure of about $1 \mathrm{mg} / \mathrm{m}^{3}$ (personal samples) for an average of 5-7 years revealed detrimental effects on four psychomotor or neurobehavioural tests. One study ${ }^{29}$ suggested that the eight hour time weighted average (TWA) airborne concentration of manganese in total dust should not exceed $0.12 \mathrm{mg} / \mathrm{m}^{3}$ during a working lifetime of 40 years. In 1992 at a symposium on manganese toxicity in Paris, papers from Canada, Italy, and Sweden independently corroborated the finding that early CNS effects can be detected at manganese exposure levels much lower than previously thought. The same year, ACGIH proposed an intended change for its TLV-TWA by decreasing it to $0.2 \mathrm{mg} / \mathrm{m}^{3}$ (as $\mathrm{Mn}$ ) for elemental and inorganic manganese compounds.

Despite early and abundant documentation of detrimental effects of manganese on lungs and CNS, control strategies have been slow to develop. This in part has been due to the slowness in understanding CNS effects occurring at less than $5 \mathrm{mg} / \mathrm{m}^{3}$ and the non-uniform acceptance of that evidence, which is reflected in widely varying standards for manganese exposure across jurisdictions. One of the major gaps in the knowledge was the lack of dose-response relationships due to the combined effect of inadequate study design and poor characterisation of exposure. It has been almost 10 years since the publication of Roels' work and that of others which led ACGIH to adopt its current exposure threshold value of 0.2 $\mathrm{mg} / \mathrm{m}^{3}$ in 1995: yet US-OSHA still has a $5 \mathrm{mg} / \mathrm{m}^{3}$ (ceiling) as its permissible exposure limit, in the UK and Australia the standard is $5 \mathrm{mg} / \mathrm{m}^{3}$ ( $1 \mathrm{mg} / \mathrm{m}^{3}$ for fume or $\mathrm{Mn}_{3} \mathrm{O}_{4}$ ), in Germany the MAK is $0.5 \mathrm{mg} / \mathrm{m}^{3}$, and in Sweden the TLV-TWA is $0.4 \mathrm{mg} / \mathrm{m}^{3}$. Recently the current ACGIH TLV-TWA has been challenged by industry and there is now considerable debate about the basis for the standard. If the currently adopted ACGIH TLV-TWA proves correct, many manganese exposed workers around the world will have experienced a further decade of unnecessary elevated neurotoxic risk.

\section{CONCLUSION}

In most instances there appears to be a very long time period between the first appearance of evidence linking an agent to a disease and the eventual appearance of a control strategy with which the various affected parties can feel a relative degree of comfort. In part, this is because it takes time to accumulate strong scientific evidence of harm. As confirmatory evidence begins to appear it usually stimulates debate and the debate in turn leads to public and business awareness and then pressure for a suitable strategy for control, and this also takes time. While there are many influences on the decision to control and to what level, it seems clear that, despite some US and European companies voluntarily introducing exposure controls, in general, in the absence of specific regulation, little change occurs at the workplace level. Unless there is intense public pressure, there is a general tendency for industry to try to slow down and delay the introduction of control strategies and regulation, challenging it on scientific then economic grounds and, in North America, at least, resorting to the courts if necessary. For example, there are currently two court challenges contesting ACGIH's right to publish its recommended TLVs (see ACGIH Worldwide Today Spring 2001:9(2)).

The cases with the longest latency period from first evidence to control have occurred when the evidence appeared 
in the early part of the 20th century when little specific occupational health legislation existed. Legislation tended to be very general and largely aimed at safety. The 1970s to ' 80 s saw the development of strong health and safety regulating agencies, like OSHA, HSE, DFG, and SCOEL backed by research and information organisations like NIOSH. These agencies introduced new improved occupational health and safety legislation with health specifically targeted. An example where evidence was first cited after 1970 shows that with these agencies and mechanisms for dealing with health hazards in place, control strategies can now be introduced much more quickly. For vinyl chloride monomer, first reports appeared in 1974 and preliminary restrictive control measures were legislated in 1975. There was little argument over scientific evidence, only the economics.

While the situation is improving in developed countries, there are signs that improvements will not be uniform across workplaces given the report by Topping et al, which brings with it the clear message that regulation without targeting educational programmes at specific affected companies will not be totally effective. In developing countries, although the same evidence is available, too often economic considerations are allowed to be barriers to improvement, as is the lack of modern occupational health and safety legislation and effective enforcement agencies.

Finally, with the benefit of strong modern legislative and regulatory powers, expert advisory bodies, international cooperation, a large volume of ongoing research, and the ability to quickly disseminate findings, evidence of workplace derived disease should be much more rapidly translated into preventive control strategies than in the past. However, it remains to be seen if this is going to be the case.

\section{Authors' affiliations}

D K Verma, Program in Occupational Health and Environmental Medicine, McMaster University, 1200 Main Street West, HSC-3H50, Hamilton, Ontario, Canada L8N $3 Z 5$

J T Purdham, Gage Occupational and Environmental Health Unit, Department of Public Health Sciences, University of Toronto, 223 College Street, Toronto, Ontario, Canada M5T 1R4

H A Roels, Industrial Toxicology and Occupational Medicine Unit School of Public Health, Université catholique de Louvain, B-1200 Brussels, Belgium; on sabbatical leave 1999-2000 at McMaster

University, Hamilton, Ontario, Canada

\section{REFERENCES}

1 Greife A, Halperin W, Groce D, et al. Hazard surveillance: its role in primary prevention of occupational disease and injury. Appl Occup Environ Hygiene 1995;9:737-42

- This paper describes how hazard surveillance, a composite of several separate pieces, including identification and control of hazard, characterisation of exposed population, use of protective equipment and other control technologies, and evaluation of intervention strategy effectiveness, is used in prevention of occupational disease and injury.

2 American Conference of Governmental Industrial Hygienists Documentation of the TLVs and BEls, 6th ed and Supplements. Cincinnati, Ohio: ACGIH, 2000 (available on CD-ROM)

This is a most useful publication which provides detailed documentation, with references, of the basis of the proposed ACGIH threshold limit values for chemicals and physical agents.

3 Topping M. Occupational exposure limits for chemicals. Occup Environ Med 2001;58:138-44.

This publication is an excellent overview of the standard setting process and the issues involved in the UK and the European Union.

4 Deutsche Forschungsgemeinshaft. List of MAK and BAT values 2000. Maximum concentrations and biological tolerance values at the workplace. Commission for the Investigation of Health Hazards of Chemical Compounds in the Work Area, Report No. 36, Wiley-Verlag GmbH, VCH, Weinheim, Germany, 2000.

5 European Union. Methodology for the derivation of occupational exposure limits: key documentation. Luxembourg: European Commission, 1999. (Report EUR 19253 EN).
6 Hoeger FD, Rampy LW, Rausch DA, et al. Industrial perspectives: translating the knowledge base into corporate policies, programs, and practices for health protection. In: Lippmann M, ed. Environmental toxicants: human exposures and their health effects, chapter 30, 2nd ed. New York: John Wiley and Sons, 2000:969-80.

This chapter presents an overview of the considerations involved in establishing policies, programmes, and best practices for the manufacture, use, and disposal of chemicals, from a corporate perspective.

7 Topping MD, Williams CR, Devine JM. Industries perception and use of occupational exposure limits. Ann Occup Hyg 1998;42:357-66.

This paper describes the results of interviews held with 1000 randomly selected chemical users in the UK to determine how they obtained information on harmful properties of chemicals they were using, how they decided on control measures and to assess their knowledge of COSHH regulations and OELs.

8 Maltoni C, Lefemine G, Gilberti A, et al. Carcinogenicity bioassays of vinyl chloride monomer: a model of risk assessment on an experimental basis. Environ Health Perspect 1981;41:3-29.

9 NIOSH. Engineering control in the plastics and resins industry. Cincinnati, Ohio: DHHS(NIOSH) 1978: Publication No.78-159

10 Case RAM, Hosker ME. Tumours of the urinary bladder in workmen engaged in the manufacture and use of certain dyestuff intermediates in the British chemical industry: Part 1 , the role of aniline, benzidine, 1-naphthylamine, and 2-naphthylamine. Br J Ind Med 1954;11:75-104.

11 Castleman BI, Murray R. Asbestos and cancer: history and public policy [letter]. Br J Ind Med 1991;48:427-32.

An exchange of letters which highlight the two sides of the debate about asbestos health effects and regulation. It contains key references on the health effects of asbestos.

12 Walton WH. The natural hazard and assessment of occupational exposure to airborne asbestos dust: a review. Ann Occup Hyg 1982;28: 117-247.

- An excellent paper describing and discussing the important issues concerning the measurement of asbestos exposure.

13 Seaton A. Silicosis. In: Morgan WKC, Seaton A, ed. Occupational lung diseases, chapter 12, 3rd ed. Philadelphia: WB Saunders Co, 1995.

14 Chen W, Zhuang Z, Attfield MD, et al. Exposure to silica and silicosis among tin miners in China - exposure-response analyses and risk assessment. Occup Environ Med 2001:58:31-7.

15 Soutar CA, Robertson A, Miller BG, et al. Epidemiological evidence on the carcinogenicity of silica: factors in scientific judgement. Ann Occup Hyg 2000;44:3-14.

- This is a very good review paper which discusses the most recent epidemiological studies related to the issue of silica, silicosis, and lung cancer.

16 Checkoway $\mathbf{H}$, Franzblau A. Is silicosis required for silica-associated lung cancer? Am J Ind Med 2000;37:252-9.

17 Landrigan PJ. Benzene and blood: one hundred years of evidence. Am J Ind Med 1996;29:225-6.

18 Lauwerys RR, Hoet P. Industrial chemical exposure: guidelines for biological monitoring, 3rd ed. Boca Raton, Florida: Lewis Publishers, CRC Press LLC 2001:202-18.

- This book is one of the best sources of information on biological monitoring for assessment of chemical exposure for many substances, including, in this instance, benzene.

19 Nieuwenhuijsen MJ, Burdorf A. Three centuries of research on baker's asthma: how close are we to prevention? Ann Occup Hyg 2001;45:85-7.

20 O'Hollaren MT. Baker's asthma and reaction secondary to soybean and grain dust. In: Bardana EJ, Montanaro A, O'Hollaren MT, ed. Occupational asthma, chapter 9. Philadelphia: Hanley \& Belfus, 1992.

21 Musk AW, Venables KM, Crook B, et al. Respiratory symptoms, lung function and sensitization to flour in a British bakery. BrJ Ind Med 1989;46:636-42.

22 Burstyn I, Teschke K, Kennedy SM. Exposure levels and determinants of inhalable dust exposure in bakeries. Ann Occup Hyg 1997:41:609-24.

23 Burns W, Robinson DW. Hearing and noise in industry. London: HMSO 1970.

24 Berger EH. Noise control and hearing conservation: why do it? In:Berger EH, Roystes L, Royster J, et al, eds. The noise manual, 5th ed. Fairfax, Virginia: AlHA Press, 2000:1-17.

25 NIOSH. Criteria for a recommended standard: occupational noise exposure revised criteria. Washington, DC: DHHS (NIOSH) 1998: Publication No. 98-126.

26 Wolters EC. Manganese-induced parkinsonism. In: Yasui M, Strong M, Ota K, Verity MA, ed. Mineral and metal neurotoxicology. Boca Raton, Florida: CRC Press, 1997:319-25.

27 US Environmental Protection Agency. Health assessment document for manganese. Final report EPA-600/8-83-013F. Environmental Criteria and Assessment Office, Cincinnati, Ohio, 1984

28 Roels H, Lauwerys R, Buchet JP, et al. Epidemiological survey among workers exposed to manganese: effects on lung, central nervous system, and some biological indices. Am J Ind Med 1987;1 1:307-27.

29 Roels HA, Ghyselen P, Buchet JP, et al. Assessment of the permissible exposure level to manganese in workers exposed to manganese dioxide dust. Br J Ind Med 1992;49:25-34.

- This work was largely responsible for the current ACGIH TLV-TWA. It demonstrates that total manganese dust exposure is the important fraction to regulate. 


\section{QUESTIONS (SEE ANSWERS ON P 174)}

(1) The process that translates evidence of hazardous occupational conditions into strategies for prevention is:

(a) Dependent entirely upon scientific evidence

(b) Dependent on the ability of industry to make necessary changes

214 (c) Purely a result of public pressure and socioeconomic conditions

(d) A result of the compromise between scientific evidence and social and economic factors

(e) Sometimes influenced by public perception of risk

(2) Determine if the following statements are true or false:

(a) Evidence comes from epidemiological studies

(b) Evidence could never come from medical and related biological monitoring

(c) Information from unions and workers' complaints would be ignored since they may not be reliable

(d) Evidence can come from routine occupational hygiene monitoring

(e) Evidence from animal toxicological studies would not be used for prevention strategies because it is not relevant to humans

(3) Preventive control strategies:

(a) Take place at the regulatory and workplace level

(b) Usually require a ban on the use of a substance if it is carcinogenic

(c) For regulatory purpose can include establishing exposure limits, provision of specific guidelines, and, in some cases, prohibition on manufacture, use, and import

(d) In the workplace include engineering controls such as ventilation, substitution of hazardous materials, and use of personal protective equipment

(e) Do not include education and training

(4) The case studies illustrate that: (a) Evidence for detrimental effects such as baker's asthma from exposure to flour dust led to immediate and universal implementation of control strategies which have been strictly enforced

(b) Evidence of the bladder carcinogenicity of $\beta$-naphthylamine led to a ban on the manufacture and use of the substance in the UK

(c) It took over 50 years from the first evidence of carcinogenicity of vinyl chloride to the implementation of strict exposure standards to prevent this

(d) Compliance with current standards for noise exposure will ensure full protection of hearing over a working lifetime

(e) Biological monitoring of workers exposed to benzene at the currently recommended occupational exposure limit of $0.5 \mathrm{ppm}$ cannot be done by measuring phenol in urine

(5) The case studies demonstrate that:

(a) In developed nations much progress has been made in controlling exposure to silica; however, silicosis still remains a significant concern

(b) Silica exposure can cause silicosis but there is no evidence that it may also cause lung cancer

(c) Asbestos exposure in workplaces in the developed nations has been significantly reduced over the years. This was achieved through a combination of strict regulations and a great reduction in use

(d) The use of asbestos in developing nations is decreasing and thus should not present any significant health hazard for workers in those countries

(e) Inhalation of manganese dust can cause pneumonia and pneumonitis as well as a Parkinson-like neurological disorder called manganism 